\title{
Erratum: A certain structure of Artin groups and the isomorphism conjecture
}

http://doi.org/10.4153/S0008414X2000036X

\section{S. K. Roushon}

In the original publication of this article [1], there are several instances where the phrases "the following Table" or "the following Figure" refer to a Figure or Table that was placed before the relevant text. The updated listing below clarifies that corresponding Figure or Table.

Theorem 3.4: The text “... as given in the following Table" refers to Table 3, which appears on the same page but above the text.

Section 4 Artin Groups and Orbifold Braid Groups: The text in the fourth paragraph "... as in the following picture" refers to Figure 1, which appears at the top of the following page.

Underneath Figure 2, the first line of text states “. . the following picture”, referring to Figure 2 above it.

Theorem 4.1: The text “...the following Table" refers to Table 4, which appears on the same page but above the text.

Proof of Proposition 4.1: The text "...the following Figure" refers to Figure 4, which appears on the same page but above the text.

The publisher regrets the discrepancy.

\section{Reference}

[1] S. K. Roushon, A certain structure of Artin groups and the isomorphism conjecture. Canad. J. Math. (2020). http://doi.org/10.4153/S0008414X2000036X

Published online on Cambridge Core December 11, 2020. 